\title{
Works from the War between Houses and Wind Ben Marcus
}

\section{The Strategy of Grass}

The smasher was the first grass-guard of American shelters. Often accompanied by a dog, the girl wielded her shade-stick so that the sun might never collaborate with the grass in destroying the house. This was not the first time houses were under attack from outside forces. House crushing schemes were often observed to no avail; indeed, shacks were burnt nightly by sunwater bogged upon grass, fire-chalk scratched out tents and sheds, even cabins were scorched by greenweeds until the girl became employed on American lawns. The technique of shade has since this period allowed houses to flourish, with the dog being designated as the first shade-chaser, or, more formally, the Person. Although not human, the person holds an innate need to save the house.

Shade has throughout known times warded off enemies, particularly those dispatched by the fiend, if the fiend is defined as any item of great or medium heat, extending from a wire. Although shade is technically gray in color, red shades permeate the lawns of Denver, and a colorless, cooling shade has been observed in the seventeen primary settlements of Illinois. While shade was first disproved by Jerkins in his FARM EXPERIMENTS (in which he claimed that shade was a black sun welt that could be soothed with water and straw), it has currently gained favor in the communities due to the expert wielding of the sun-smashing girl. No sun is actually ever touched by this employee. The dramatic nomenclature indicates merely a deft skill with the stick. A shade-sprayer by trade, her work involves house-dousing when the sun is brightest. The dog stalks these cooling skins across the lawn or over sections of house, acting also as a shade dragger when the girl is at work beneath the house. Although shade is mistrusted by many occupants, and has rarely been selected as a primary weapon, it must not be overlooked as a key defense against objects that might burn in to take the house from the air, in secret agency with the wires of the hallowed sun.

Since grass preceded the house, and is considered to be a grain yet older than wood, we must wonder whether the grass wars of the 1820s contributed to the brief disappearance of houses observed during this era. 
That no shelters were in view either indicates perhaps a correlation with the Great Hiding Period of those same days.

Lawn-boys were numerous in Ohio in the early weeks of the first seventies. Boys and their counterparts were dispatched across lawns to serve as wind poles during the street storms of this period, and the shorter, sturdier boys (maronies) were often the first to blow back into the houses. This explains in great detail the rugged ornamentation of certain shelters in the middle west, particularly those houses that contain chronicles etched into the awnings. The taller boys, the skinnier ones, could more successfully deflect wind from the house, and they became better known as stanchers, although salaries were meager. During the chalkier street storms, however, the boys went unfed and often starved upon the lawn, creating skin flags, or geysers of bone and cloth, which during more elastic storms could ripple back and snap windows from a house until glass spilled into the air, cutting down the insect streams. What was left of the boys was then smothered by this powdered glass and air blood that fell upon them, rendering a burial site at each house. Boy-piles on grass were richest after storms, and planting was heaviest until this fertilizer was rifled by scavengers-often young girls and their animal sisters, who dragged the soil away in sacks and wagons.

\section{Air Dies Elsewhere}

When air kills itself the debris settles onto the grass, sharpening the points. Dogs may not walk on these areas, nor may they ever even observe the grass without pain in the chest and belly. When children sleep on the lawn the funeral passes just above their heads in a cross-wind with the body. Funerals generally are staged in pollinated wind-frames, so that the air can shoot to the east off of the children's breath, dying elsewhere along the way, allowing fresh, living air to swoop in on the blastback to attack the house. This funeral chasing ability of children explains why they are allowed outside during the daytime and back in again the next day. The Mother cleans the child's mouth with her finger and is said to act as a transom for the warring agencies of wind. This is why she is placed in the window, wires bobbing from each hand, bowing forward against the glass.

Other forms of sleeping also calm the sky. Wealthy landowners hire professional sleepers to practice their fits on key areas of the grounds. The best sleepers stuff their pockets with grass and sleep standing up. Many 
amateur sleepers never wake up, or never fall asleep. If a professional wakes and discovers a protector still sleeping, or unable to sleep and making an attempt of it-in the shed, for example, downwind of the house-he is permitted to practice smashes upon this body. Freelancers take their dream seizures near the door, and storms are said to be held in abeyance. They are paid according to success. Much booty has been disbursed, but no one has ever succeeded to sleep so deeply that the house is not smashed upon waking.

If dogs or parts of dogs are ever studied, it will be their feet. The primary transmission has occurred between grass and the paw. When we kill dogs we kill them because we are sad. SADNESS develops in and outside of the house, either just after entering or just after leaving. These are also the times of war when we encounter dogs and have the opportunity to act upon them. The feet of dogs are soaked in Corey, a chemical produced in grass after air has mixed the shape of the house. Collectors believe that feet grow heavier after being removed, lighter when touched, and remain the same when left alone. This is also true of sadness and wires.

\section{Rule of Exit}

When the sun's wires are measured, we discover the coordinates for a place or places that shall heretofore be known as perfect or final or miraculous. The house shall be built here using soft blocks of wood and certain solidified emotions, such as tungsten. By nightfall the bird-counter will collapse, and a new man must be placed at the road to resume the tally while the construction continues. His harness will be a great cloth fixture bound unto his head, to protect his mouth from the destroying conflicts, lest strong birds sweep in on the wires to knock back the homes. Every house prayer shall for all time ever read thusly:

Please let the wires not have been crooked or falsely dangling or stretched by the demon sun, let our measurements be exact and true, and bless our perfect place with abundant grasses. Cover us in shade so that we are hidden in your color. Hide us from birds and wires and the wind that sends them. Let smoke conceal us during the storm life, and give us strong walls. Let not any stray wind break us down and we will honor you. Bless us and a great shelter will be made for you in the new season. Help us thrive. We lie low here in the place that you have given us. Please remember 
that you have killed us and you can kill us and we wait and long in our deepest hearts to be killed only by you. Let this be our last and final house.

Amen. 